\title{
The Mystery of Elin. Incorporating a City Cultural Program on History and Heritage into a Pervasive Game
}

\author{
María Guadalupe Alvarez Díaz \\ University of Skövde \\ Högskolevägen Box 408 \\ Skövde 54128 Sweden \\ +46500448912 \\ maria.guadalupe.alvarez.diaz@ \\ his.se
}

\author{
Marcus Toftedahl \\ University of Skövde \\ Högskolevägen Box 408 \\ Skövde 54128 Sweden \\ +46500448374
}

marcus.toftedahl@his.se

\author{
Torbjörn Svensson \\ University of Skövde \\ Högskolevägen Box 408 \\ Skövde 54128 Sweden \\ +46500448813
}

torbjorn.svensson@his.se

\begin{abstract}
This paper reports on the use of mobile terminals in historical spaces to play an adventure game, using a location-based platform to awaken the fantasy and curiosity of children about cultural heritage; the design of a mystery game as the medium to convey content along with features shared by pervasive games, such as mobile exploration, team work, and the combination of virtual and real worlds. It includes the process of adapting history to storytelling and the results of using a method to evaluate the experience.
\end{abstract}

\section{Categories and Subject Descriptors}

H.5.2 [User Interfaces]: Evaluation/Methodology. K.8.0. [Personal Computing]: General - Games.

\section{General Terms}

Performance, Design, Experimentation, Human Factors, Languages, Theory.

\section{Keywords}

Game technology, pervasive gaming, mobile games, alternate reality games, location-based games, transmediation, gamification, tourism, and cultural heritage.

\section{INTRODUCTION}

The main purpose of the Mystery of Elin project, a pervasive game played in groups of 3-4 middle school children on iPads in Skövde city center, (the game is described in more detail in Chapter 5, Balance between gameplay and story) was to find a link between narrative and gaming, as the point of departure on which to build a cultural experience. This link is probably one of the basic requirements for reaching a balance between amusement and content in a game. The link is created by using the ability of adventure games to turn players into characters, enabling the

Permission to make digital or hard copies of part or all of this work for personal or classroom use is granted without fee provided that copies are not made or distributed for profit or commercial advantage and that copies bear this notice and the full citation on the first page. Copyrights for thirdparty components of this work must be honored. For all other uses, contact the Owner/Author.

Copyright is held by the owner/author(s). IE2014, Dec 02-03 2014, Newcastle, NSW, Australia

ACM 978-1-4503-2790-9/14/12.

http://dx.doi.org/10.1145/2677758.2677768 players to become engaged in the story by progressing in the solution of quests, and blurring the line between virtual and real game worlds. This link turned a historical site into a game board by structuring the spaces, both the virtual and the real; incorporating suggestive interpretations of symbols and signs in buildings, plazas and streets.

At the center of the project were several ideas, such as conveying a game story through various media, with comic strips at the beginning to present the plot and more at the end to give sense to the conclusion of the game, simulating instant messaging that acts as a bridge between worlds and using real places intertwined with the game's virtual spaces. At a higher level there was also the idea of adapting historical events and characters; providing pieces of historical facts as game rewards and creating intriguing story elements that do not end when the game does.

Questions arose concerning the transmediation of the main character Elin, as well as the history of Skövde and its heritage, into a narration that is not an end in itself but a medium that serves a goal. Why is Elin not a martyr? How can we convey concepts such as "patron saint" in the contemporary idiosyncratic language of Swedish children, when the objective is to enable identification with the character? How far can the fantasy of players develop the story in the fictional plot?

Players visiting or living in the city of Skövde are exposed to various forms of representation of Saint Helen and the history of Skövde, through literature, video films, museum exhibitions, onsite installations and school lessons. The game, in which each participant can make his/her own interpretation of the person Elin and Skövde's history, is one of several forms employed by the municipality to promote the culture of Skövde. The first version of the game was released on June 28, 2013, in conjunction with the opening of the refurbished City Library located in Skövde's Culture Center Hall. A few weeks later the app became available for downloading from the App Store to iPad. The application continues to be available free of charge.

In the evaluation process, nearly all the players indicated that the experience was fun or a lot of fun. Interviews conducted show that participants assigned attributes from the main character to the historical figure, even though they were conscious of elements of fantasy in the story told.

\section{THE IDEA OF DEVELOPING AN APP}

During the university's autumn term of 2012, a number of discussions were held with representatives from the City Museum of Skövde, Sweden, Skövde Municipality, and the research group Media Technology and Culture (MTEC), at the University of 
Skövde for the purpose of together developing a project in which the students could also participate. As such, it would provide the appropriate environment for research in the areas of cultural heritage and game technology. The project took the form of a case study concerning a game based on a transmedial narrative. In addition, the case study included the development of a game app for iPads from October 2012 until May 2013.

The app would meet needs in areas of education, politics, economics, cultural heritage and tourism. The target group for this project was mainly children $8-12$ years of age. The objective was for participants, in the experience of the game, to identify themselves within the central city environment, by capturing their interest in the city and its history, living the culture in a form of appropriation of the city's heritage. It was expected that the app would attract Skövde's inhabitants to the city in their free time, thereby contributing, along with other activities, to the formation of a warm cultural environment that would activate the economy and provide an original and more exciting tourist experience, thus adding to the effort of building the city's image and identity.

The basis for all the efforts to promote culture by the city's municipality is included in their "Cultural Environment Program for the Municipality of Skövde" [9]. The program refers to two general functions that cultural heritage can facilitate and which are applicable to the municipality: 1) as a habitat creator and 2) as an identity constructor. In relation to the immaterial heritage, there were considerations about perspectives and stories to be told based on the significance of heritage today. With regard to the project, this meant the potential transmediation of historical figures and events, along with their circumstances, into a game world. Developers read the documentation and explored the sites, identifying and generally learning about the most significant areas of the city. The group identified a sequence of Skövde's evolution in time and the biographical information of historical characters as important aspects, creating a short list of places and buildings in the city, including historical figures, which are most relevant to the patron saint of the city, the martyr Saint Helen (skyddshelgonet St Elin).

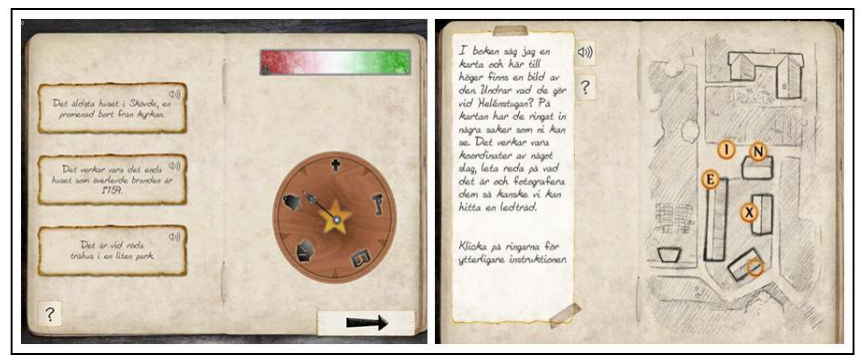

Figure 1. Navigation screen and Challenge for $\square$ Helen's cottage screen

The media form of choice was a pervasive game, because it invites players to walk around the city streets, combining the actual environment with the illusion of the game. Such an activity, where players participate in groups, is aligned with the way most visitors enjoy walking around a city, pausing perhaps for ice cream or looking at something interesting. The game is also appropriate for local families that are used to rallies and treasure hunting games, providing a fun activity and at the same time supporting learning in a place as rich in culture as the city of Skövde.
Technology considerations were made regarding the type of mobile end-user terminal as well as the development platform.

The game would use GPS tracking, as well as compass and camera, the standard features of mobile equipment. Smartphones or tablets were the two shortlist options. Tablet iPads were chosen after recommendation by the Municipality, as these terminals were becoming more and more popular in public institutions. There was a possibility for the public to borrow iPads from the city library and the tourist office, in order to play the game. The iPad provided a bigger screen for the benefit of graphics as well as the opportunity for children to use a fun portable device in teams. The terminal device was defined as the platform iPad/IOS. The game engine chosen was Unity with added plug-ins, such as image recognition along with the location-based platform features from Mobile Storytelling.

\section{WHY PERVASIVE GAMES ARE SUITABLE FOR CULTURAL ENVIRONMENTS}

Because the game world combines fiction and reality - a different experience compared with virtual reality games where the game world is totally recreated - heritage elements here acquire significance through the intrinsic values projected by fictional elements. The physical environment becomes the game board, giving, for instance, museums the opportunity to expand the limits of their walls to spaces of interest or historical locations.

Pervasive games imply a collective interpretation, as they are usually played in groups. The main pleasure of the experience comes with the immersion in the environment while solving tasks, fun activities that allow players to conceptualize the experience. The introduction to the game using comic strips encourages participants to become part of a team when they hear the main character saying: "I don't want to go asking the adults... but with your help we are going to make everything clear". The way children experience the challenge can vary, depending on the team work, particularly in this game. See the observations below, obtained during the evaluation sessions.

When designing pervasive games, it is important to focus on the educational aspects of gameplay. Effective learning by active exploration requires challenges, fantasy and curiosity [5]. Gameplay is directly related to the fun, but designing it for learning requires considering that the mental challenge must be connected to the physical activity, in the presence of the cultural heritage, real and/or virtual. Other aspects, such as social interaction, collective effort, and using the curiosity generated by the gameplay to capture the interest in wanting to know more, are also important.

\section{ADAPTING HISTORICAL ELEMENTS TO A CONTEMPORARY ENVIRONMENT}

As a method, the development group first brought the game's general concepts to the table, assembling and visualizing the start items for building the gameplay and the ideas for the story.

The adaptation method consisted of outlining a game world formed by two types of elements: real, i.e., physically identifiable, and fictional. The fictional plot, characters and their situations, takes place in a real environment. For instance, game-writer students suggested that a type of chat messaging format, such as 
Skype, could be used by the main character, Elin, to interface with the players while they walk around the streets.

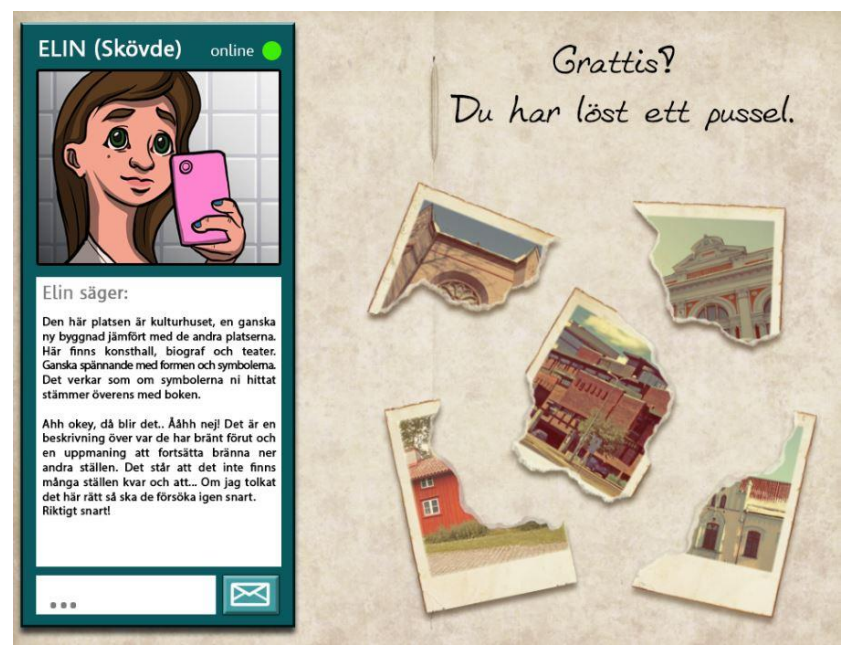

Figure 2. Elin's chat interface

The initial plot begins with a girl who has been kidnapped after leaving the library. She has a book full of symbols and enigmas that the players must discover in the actual city. The girl, Elin, interprets the symbols and enigmas from the book, realizing - by playing the game - that it is the diary of a person who keeps burning the city in order to look for some hidden gold. The game ends when the players together solve this mystery. Then Elin decides to bury the book, protecting the city with the help of the players.

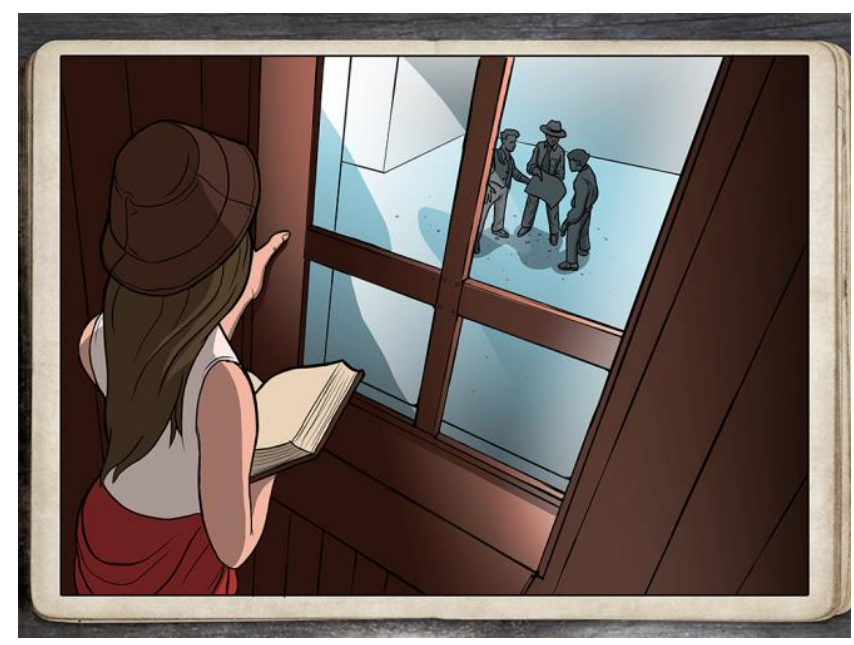

एس山سWFigure 3. Elin from the introductory comic strip

Elin remains hidden throughout the game, but is represented by her voice at all times; her physical features are depicted in the form of comic strips.

\subsection{Transmedial Narration}

The adaptation can also be described by reconstructing the narrative. The narrative in cultural experiences in this paper is understood as a process structured as layers. The given historical documentation of a chosen heritage constitutes the basis of all the layers, as well as texts derived from historical sources. Following a layer would be a proposed version with plot and story involving a medium or a collection of media. This version is determined by a contemporary interpretation of the heritage story, and aligning the content to the intended experience for the players, as well as the application of suitable technology. In addition, this layer can contain multiple narrative versions with their respective media. The next layer contains those multiple versions, but transformed by the intervention of the players who select one medium, or several media, that better suits them. As a top layer, participants in the narrative experience determine which of the proposed alternatives would define the destiny of the narration or create their own version with elements from the various media. At this level in the narration, options expand due to interaction. The interpretation can be personal and/or collective; the participant in the experience of the game can drop the story or take it to an end. The narrative can be regarded as a puzzle completed by pieces of a constructed experience.

In the reconstruction of this narrative, the first level identified is the historical background. According to the references available to the game-writer students, included in "The Cultural Environment Program for the Municipality of Skövde" [9], pilgrimage and trade probably laid the foundation for the city of Skövde around 1400. References to the saint have been taken from the legend written by Bishop Brynolf in the city of Skara, who documented The Legend of Saint Helen in 1281. Without being able to confirm the historical facts, tradition refers to the following about Saint Helen of Skövde:

- Elin existed and had a family; she was a widow with a married daughter.

- $\quad$ Elin performed an act of charity by donating all she owned to the church.

- Elin was accused of murder and sent on a pilgrim's journey to the holy land.

- Sweden's first archbishop, Stefan, received papal permission in 1164 to worship Elin as a saint.

- $\quad$ Elin is associated with the market held at the place for Elin's pilgrimage, as well as her grave and spring.

A further step in Elin's history is her legend:

- Elin was a generous and good person.

- Elin was a rich widow whose daughter was the victim of a violent husband.

- Elin was accused of ordering the murder of her daughter's husband.

- $\quad$ Elin went on a pilgrim's journey to Jerusalem.

- Elin was murdered, presumably by the family of her daughter's husband.

- $\quad$ Elin performed three miracles.

In the process of adapting the notions of history to the story told in the game, the following elements have been transformed:

Table 1. Adaptation of historical elements

\begin{tabular}{|l|l|}
\hline Elin murdered & Elin has disappeared \\
\hline Elin martyr & Elin is hunted, needs help \\
\hline $\begin{array}{l}\text { Elin lived in the 12th } \\
\text { Century }\end{array}$ & Elin disappears in time and space \\
\hline
\end{tabular}




\begin{tabular}{|l|l|}
\hline $\begin{array}{l}\text { Elin performed three } \\
\text { miracles }\end{array}$ & $\begin{array}{l}\text { Elin is brave, courageous, cool, } \\
\text { energetic }\end{array}$ \\
\hline Elin is a saint & $\begin{array}{l}\text { Elin protects the city. Her power is } \\
\text { based on her skill rather than } \\
\text { saintliness }\end{array}$ \\
\hline Pilgrimages & Elin is followed in a joint adventure \\
\hline $\begin{array}{l}\text { A fire consumed } \\
\text { Skövde in 1759 }\end{array}$ & Enemies of Skövde try to find gold \\
\hline $\begin{array}{l}\text { Symbols such as the } \\
\text { fenix rising }\end{array}$ & Renewed city born from the ashes \\
\hline $\begin{array}{l}\text { City's historical } \\
\text { moments }\end{array}$ & $\begin{array}{l}\text { Clues in the diary help heroes and } \\
\text { villains find the meaning to all the } \\
\text { symbols }\end{array}$ \\
\hline Treasure of Timboholm & Hidden gold \\
\hline
\end{tabular}

During the game, the flow of navigation-challenges-reward repeats five times with variations in the number of tasks and types of challenges at each site; for instance, to identify the location of a site, the player needs to discover clues, follow a compass direction, walk around to find the site and then stand there. The challenges at the sites to obtain a piece of the puzzle are, among others, to count symbols, discover patterns, find items, identify signs and see them through the camera.

The main character Elin "chats" clues to resolve tasks while players suggest inputs found in the real world, simulating a seamless dynamic communication. With every task the player solves, Elin receives elements to reconstruct the story. The player is a virtual member that participates from the first person perspective and explores the game world by moving around. In the interviews conducted during the game evaluation, players affirmed that resolving quests was important to them because they were helping Elin to figure out the mystery - "Girl who needed help and helped us a lot" -. Winning a piece of the puzzle was achieved with a sense of pride for doing something well for the city. Players showed attentiveness during evaluation sessions, when new pieces of information, basically historical facts, were given as rewards.

The initial plot and the conclusion of the story are long unalterable segments that can be better achieved using a comic strip, a graphic style often welcomed by children. The events associated with each piece of the puzzle do not require a sequence, but they are connected in a set order to facilitate the handling and progression of larger groups of players across the five different sites. to different versions from the various media. Some visited the exhibition before or after they played the game. Participants from school groups even learned about the history of Skövde and the legend of Elin in class, prior to playing the game.

\section{BALANCE BETWEEN GAMEPLAY AND STORY}

When the game is initiated, the voice of a girl asking for help through an instant messaging chat draws the attention of players to a comic strip that describes the initial plot and sets them on track to the first site. The game is structured as a progressive experience, thus defining the order in which players will face challenges and making it possible to construct a sequence of events. The following figure is a segment of the game flow that illustrates the principal actions.

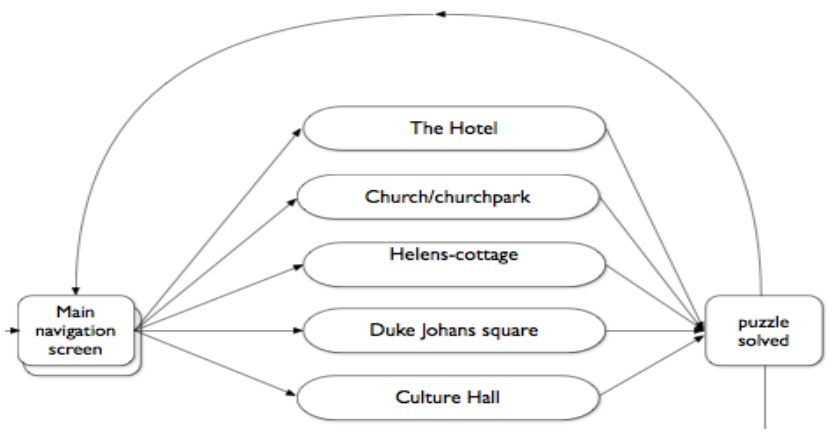

Figure 4. Extract from The Mystery of Elin's game flow

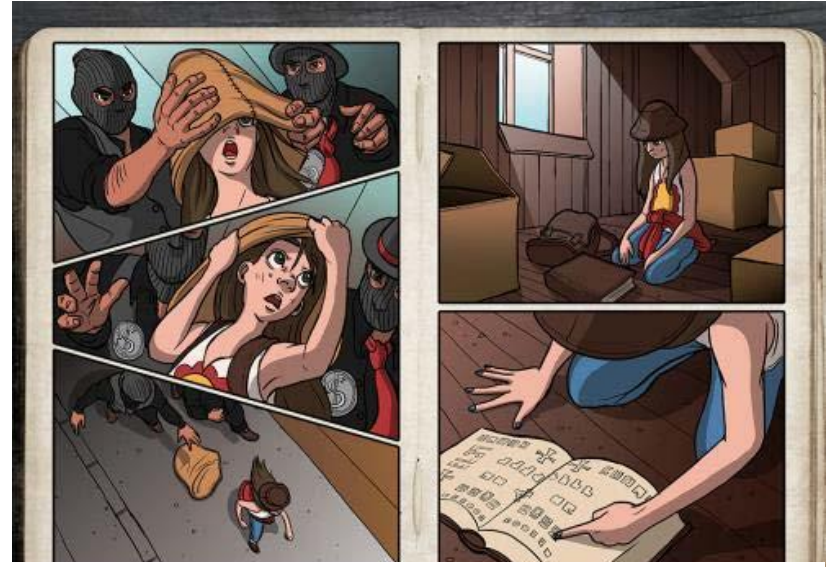

Figure 5. Part of the introductory comic strip

Visual communication elements selected by game developer students played an important role in the storytelling as well as in the gameplay. By applying symbols and codes of contemporary society and combining them with icons, objects, figures and forms easily identifiable in central Skövde, designers found an effective way of communicating content and the player enjoyed some artful challenges. Elements such as the city fire of 1759 or references to the discovery of an important ancient gold treasure are repetitive throughout the game, due to their importance in the history of the city. At some instances, those elements, in graphic form, in text, as objects, or symbols in the real environment, are provocatively hidden to stimulate free associations, since elements spread throughout the game world are meant to be captured when exploring the space. 
At the level design stadium of development, several historical locations were identified in the center of Skövde. Calculations were made to produce a game that continued for half an hour to one hour. Distances, traffic, accessibility and clearance were taken into consideration, in order to create a smooth progression between the following five sites: Hotel Billingen, Saint Helen's Church, Helen's Park, Duke Johan's Square with the former town hall (Rådhuset) and, finally, the Culture Center Hall that contains a theater, library and cinema. However, circumstances such as church restoration work and sign renovations that took place during the summer of 2013 presented a challenge and somewhat altered the game's route and tasks at some of the locations.

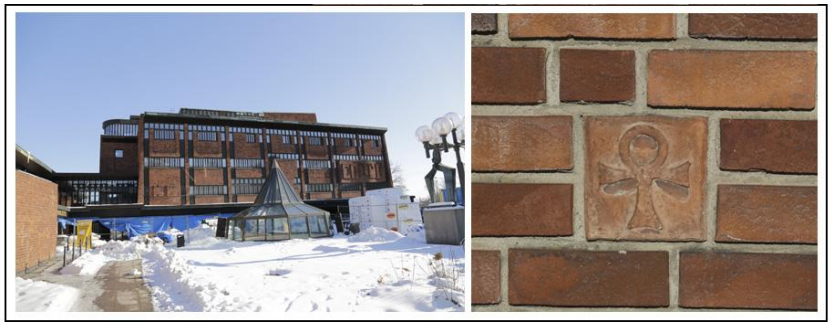

Figure 6. Culture Hall with Ankh symbol

The story is conveyed using a combination of proposed and explicit clues; those that Elin directly provides and those that may or may not be seen by the player, but were included in the level design, such as Egyptian symbols of the fenix, referring to the fire that destroyed the city in the 18th Century, or the Ankh sign, referring to the architectural style of the Culture Center Hall. Some clues were also combined with challenges, like the icons representing each of the five sites in the user interface compass.

The story told goes beyond setting a context and providing game elements originally adapted from the history of the city. An effort has been put into making them more playful; for instance, Elin is not a saint martyr, but a brave girl who is being hunted and needs help.

\section{EVALUATION}

The use of digital mobile games, such as The Mystery of Elin, as a media to awaken the fantasy and curiosity of children about a specific subject, is proving to be appropriate, which the evaluation confirms, especially when the game challenges their knowledge and background in an amusing collective experience. It is central to the experience that the players have fun and can understand the purpose of the story. The evaluation shows that much of the success of this experience depends on the ability of game designers to integrate knowledge and establish a positive connection with Skövde's city center and with its patron saint Elin; although there is more focus on the overall cultural development of the city to which the game experience is an important contributor.

A social research methodology was applied using a crosssectional design and a combination of methods for gathering information applicable to mobile playing environments. In a first part, quantitative methods were applied to gather and interpret data for the objectives that were aimed at knowing whether the app fulfilled its objectives. A second part was a combination of quantitative and qualitative methods for the developer's interest in transmedial narration.

The selection process started with some general groups of targeted players; children and young people living in the community as well as tourists visiting Skövde. From the three main variable feedback groups of players, identified as school groups, families, friends, and tourists, it was the tourist group that was harder to observe, contact or interview, followed by families and friends, due to the need of a promotion program that would inform participants about the existence and availability of the game. There were nine members of families and friends that were registered in the evaluation process. School groups were the most accessible, due to the possibility of directly informing the school administration in the community about the educational benefits of the game.

Three techniques were applied to obtain information; individual questionnaire distributed directly after the game, a semi-structured recorded interview after the game session, and a systematic observation. In the sessions with families and friends, the primary technique was the participatory observation, while in sessions with school groups, the questionnaire and interviews were used.

\subsection{Results of the game experience}

These results have been generated on the basis that school participants in the evaluation represented $15 \%$ of all children 8 years old in the municipality of Skövde. According to Statistics Sweden, SCB [4], 555 children lived in the municipality in 2012. Eighty two children from four classes in two schools situated in the neighborhood of central Skövde were registered in the evaluation.

The following table shows the children's appraisal of the experience.

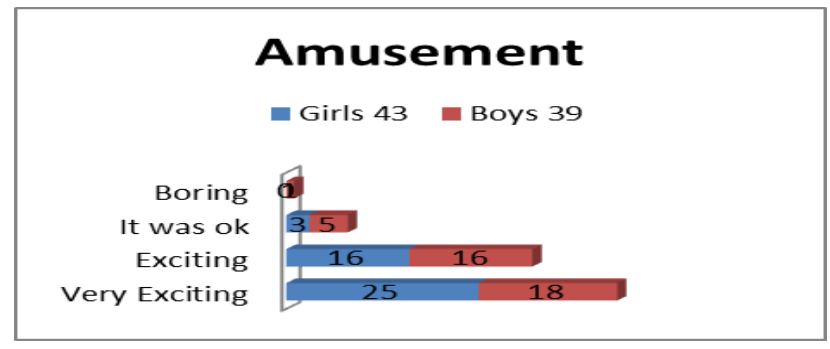

Figure 7. Statistic result of question 1 from questionnaire

The statistics of the first question in the questionnaire show that the majority of the participants rated the game experience at the two highest of four levels, as very exciting and exciting, 53\% and $39 \%$ respectively, with the girls giving the highest rate. There were 43 girls and 39 boys that played the game.

During the interviews, players spontaneously expressed how they felt about the game. The statistics in the following table represent $66 \%$ (54 players) of all the players interviewed.

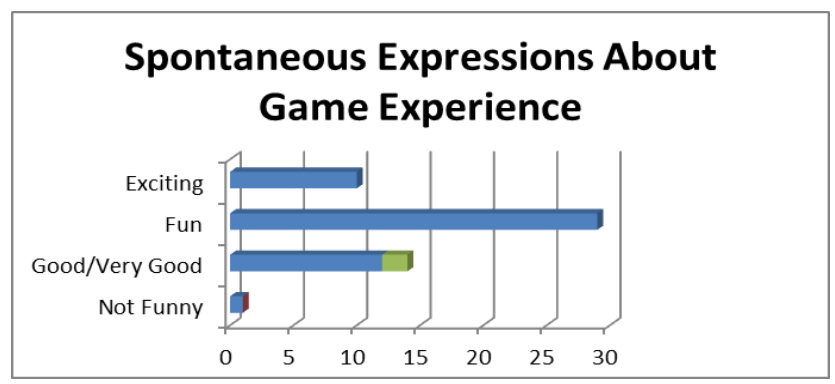

Figure 8. Statistical results from interviews 
The question in the interview: What would you do to make the game better? This question led $28 \%$ of the players ( 23 of 82 ) to a common answer which has here been interpreted as an indicator of the players' overall satisfaction. Judging by the excitement shown by the players after the game session, their expressions were understood as interest and satisfaction.

What would you do to make the game better? They could make the game longer, a continuation or a new version of the game. Some of the responses registered in the interviews include the following: "To make game longer"; "A few more stations"; "The game is too short!"; "Fun if it had more assignments"; "More puzzle pieces"; "Do the continuation"; "More tasks"; "... that the game should have more questions"; "... that we could discover more stuff "; "pretty short game." ".

\subsection{New Knowledge}

During the interviews, some expressions were interpreted as indicating the players' familiarization with the city's heritage. "The Church is the main building, where is St. Helena's statue", "Helen's Park is the main building, even more than the church, only that it didn't burn", "All buildings are places that are important for Skövde", "Hotel perhaps the most important building in the city "," In the library you can borrow books, iPad, and things like that"

Players took into consideration which building represented the city best: "Helen's Park the only one that didn't burn, is important in Skövde's history", "The church is the oldest building in Skövde."

Furthermore, there were players who expressed that playing the game had awakened their curiosity about Skövde: "I have learned a lot about Skövde, very fun to see old things and discover hidden things that are very important", "There are lots of icons in the Church"; "I noticed ... things I had not thought about", "I found more things in Skövde, to use when I grow up ... so I knew where I would go and so ... I already learned now "," I have not noticed that there were symbols on the Square ";" I never thought about the patterns in the Square ", "I noticed the signs on Helen's Park, which specify what is in there."

There were not many expressions from players during interviews or observations that indicated their interest in acquiring more knowledge about the city. However, players constantly expressed their interest in continuing to play, and resolving more tasks and puzzle pieces. Moreover, there were frequent comments about what new things the players learned about Skövde. These provided different perspectives on how well balanced the gaming elements were with the integration of content. Expressions such as "I have never seen the symbols of the library "; "I have not thought that there were marks there - Culture Center -" or the identification of Hotel Billingen as a relevant building, situating its construction in time: "I learned new things about the hotel: Roman numerals indicate when the hotel was built"; or the interpretation of symbols in the church; players interpreted that lions in the side door represent the protection of the church of the city; and finally, players manifested an overall assessment of the sites visited: "I thought Helen's cottage was the oldest house but it was the church "; "The fire was a major event in Skövde's history" ;"I learned where places were". It seems appropriate to

${ }^{1}$ These are original testimonies taken literally from transcriptions of the interviews. put the question: Can the Mystery of Elin be a Serious Game as well?

The scope of this research includes the ability of players to remember their visit to the city center rather than determining how significant the learning experience was in the game. The school groups had recently studied Skövde's history in class. The gaming experience resulted in a reinforcement of that knowledge; for example, the physical placement of historical sites, and the concrete dimensioning of buildings, objects and environment in general. There were some cases of appropriation of history and heritage, in those players who showed a positive predisposition to this type of game. In addition, there were references to other places not included in the game but remembered from the tour, such as the train station and the city's commercial center.

\subsection{Group integration and gameplay}

It was noted during the observations that players were often confused about how to proceed with the tasks. The instructions did not seem clear enough, but after some adult assistance players could move on with the game.

"We try to find things first and we read - to help her (Elin) - then, we followed the arrow and suddenly we found the place and got a

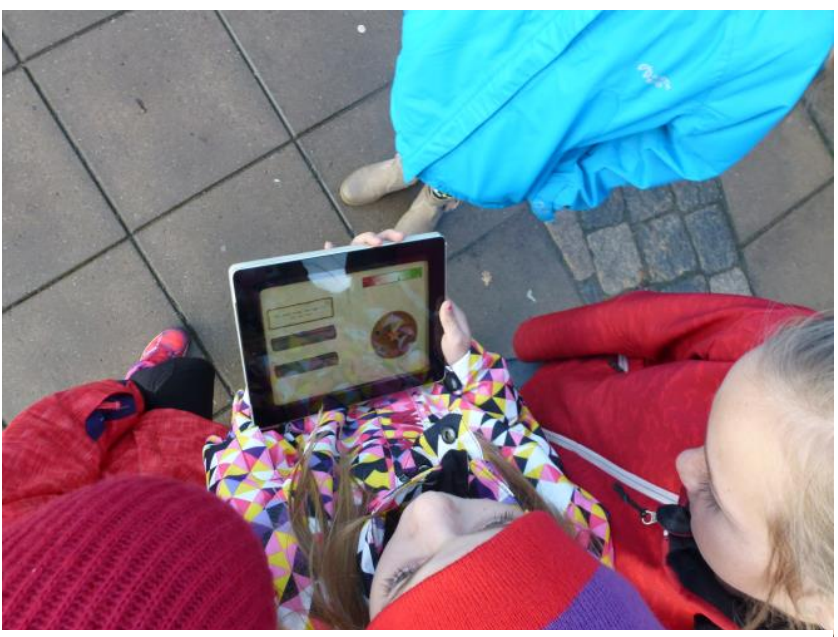

Figure 9. Navigation screen

new question". When the player came near the building, the application recognizes the site and a screen pops up. This recognition is a geo-catch feature of the platform. The new screen provides a part of the story combined with information about the site and illustrations of the new tasks.

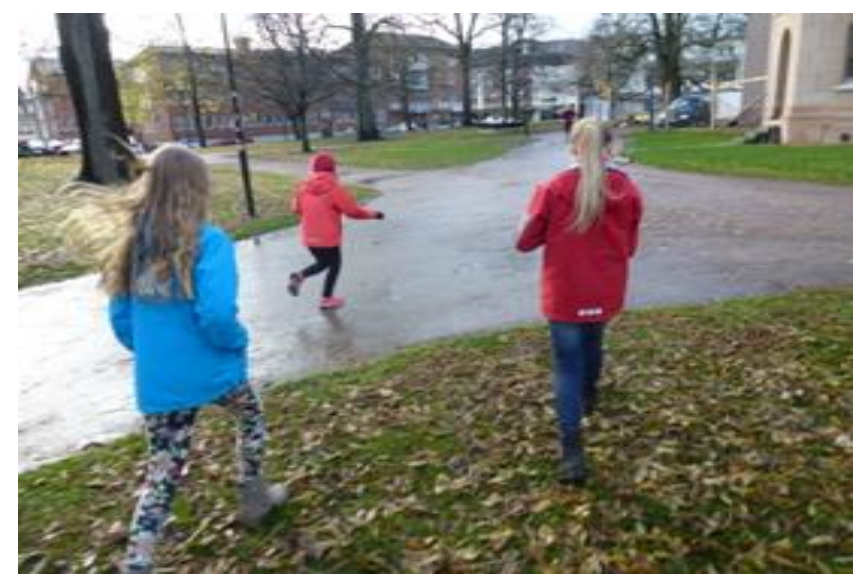

Figure 10. Finding buildings 
In the observations, it was evident that groups walked together a few meters and then players tended to disperse themselves, so when the new screen popped up the player holding the iPad was frequently the only one who heard and/or read the new screen. It was necessary for teachers and guides to encourage children to press screen buttons to repeat the voice of "Elin", the character who was providing clues to obtain each piece of the story. Other team members focused on resolving the task and frequently did not even notice that a message and a text had been given. This situation happened when searching for a new site, but it did not happen with groups of two players and less often in groups of three.

\subsubsection{Team Work}

Most comments during the interviews reveal enthusiasm and collaboration when working together. In most of the tasks, there was a member in each team that knew how to resolve a specific task. Team work here played an important role. Furthermore, the spirit of competition between groups was an incentive. Players worked better when the group members were friends or they had the chance to choose team members. Some players from school classes wondered whether the game would be as much fun if they had to play it with a younger sibling.

It was also observed that the number of players in a group often influenced the amount of involvement needed to solve the tasks and the understanding of the story. When groups exceeded three members the fourth could not see or hear as much as the others and grew disengaged, eventually losing interest in the task.

\subsection{Game Challenge}

The balance between difficulty/ease and player's amusement/interest in the game was a real challenge to game designers, due to the wide range of the targeted users' ages and the scope of the project. Mental defiance is a necessary ingredient of the game. Most players enjoy games because they provide a challenge, and when they have been solved they have learnt something, claims Richard Rouse III in his Game Design interviews [8]. During the interviews, players expressed how they had experienced the tasks at each site, as shown in the following table.

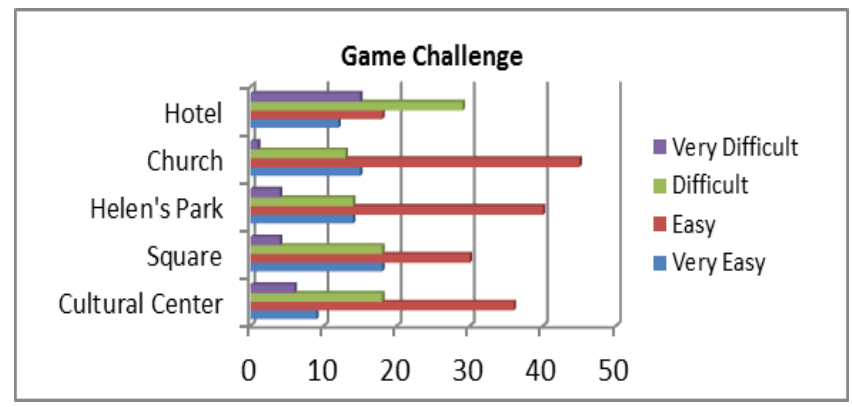

Figure 11. Game Challenge by Site

According with this table, the tasks are described as being relatively easy to solve, with the exception of the hotel. Forty four players $(36 \%)$ rated the hotel as difficult or very difficult; data recovered from the interviews show that only 6 of those players did not spontaneously express that the game was exciting, fun or good and 14 of this same group rated the overall experience as "very exciting", the highest rate for amusement from the questionnaire. The challenge was fun when the effort was repaid with the satisfaction of completion.

The challenge in Helen's Park received most of the positive comments during the interviews. "Fun", "brainteaser", "balmy", "cool" were the adjectives recovered in the interviews. It was identified as the most exciting of all the sites visited, but also confusing and tricky at times.

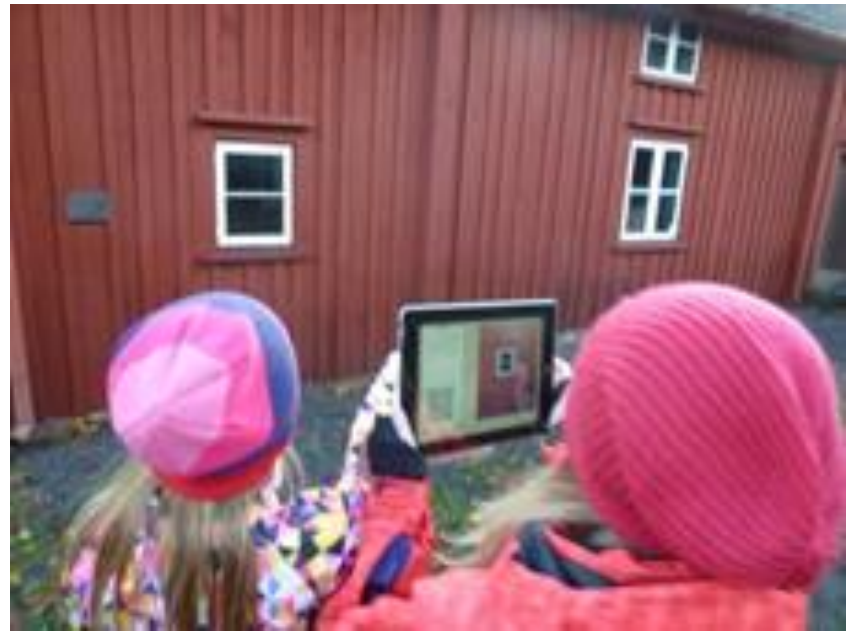

Figure 12. Image recognition

In Helen's Park, players used the IPad to identify objects based on a drawing. As if they were going to take a photo, players located the object in front of the camera so that the object was visible on the screen. The application recognizes the object and pop ups a new screen, leading the game on to a further step. This feature was possible with the imaging platform.

The illustration below shows a group trying to orient themselves with a map. It was hard for players to identify the elements of the map at the actual site. It would be helpful to let the GPS function assist with positioning the map.

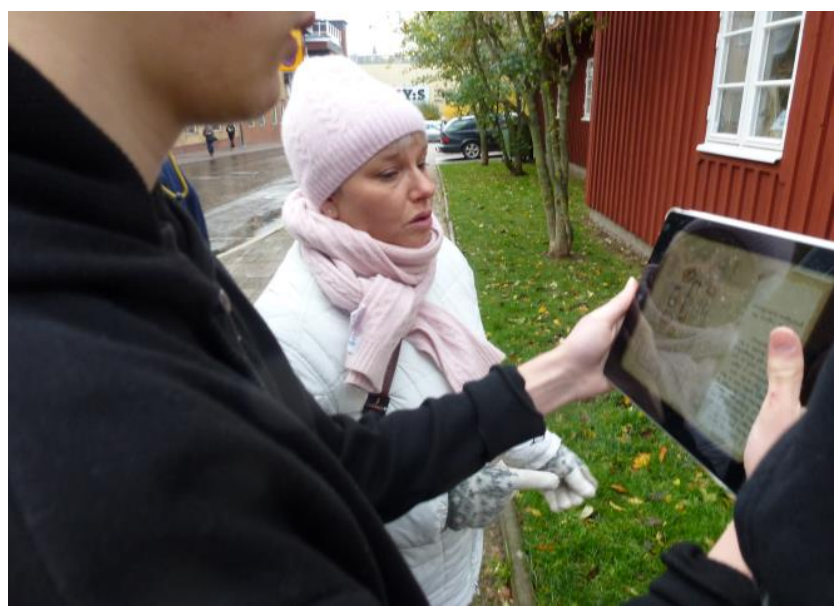

Figure 13. Using a map

\subsection{Results of Transmedial Narration}

The children combined both characters, the patron saint of the city and the adventurer girl in the game. In the search for Elin's representation, players were asked to describe the main character of the game, in order to initiate the conversation during the 
interviews. Many thought that Elin in the game was the same saint as in history but living an episode of her childhood, and expressed their sorrow for the tragic end of her life.

Most players identified Elin as a brave girl. In the interviews, players assigned attributes to the character; at times when they were talking about Elin in the game, they referred to scenes in the introductory video of the museum exhibition, making it hard to determine whether they were talking about the character of the game, even though the question was specific. It often seemed that they were instead talking about what they had learnt in school and at the museum. "She talked a bit weird and sad for everything that happens..."; "She was murdered, I felt a bit nasty"; "Elin had a little strange appearance"; "Elin dared to do things".

The first question of the interview was oriented to register what the player could recall from the story, from the beginning to the end. They could recall the beginning and were able to understand the final piece of the story, which was basically due to the use of the comic strips at the beginning and the end. In those testimonies, we also recognized what was also observed; most players had a clear understanding of the plot and the start of the story, which was basically illustrated in the comic strip, however, the subsequent fragments of the story, when the clues were given on reaching the site and the puzzles were resolved by entering the right input, were not clear to all the players or not all the players were near the iPad. Most of them did not understand the entire story, maybe just the final comic strip; only the players who held the iPad all the time during the playing session could recall the entire story in detail.

The children interpreted the formal media versions as the true account, whereas the game was an imaginary story. The context in which each media displayed the content had an important role in how this content was perceived. The introductory video at the museum, the exhibition about Elin, and the materials used in the classroom lessons are described as formal media, while the game was presented to the school children as an addition to the learning experience, or, in the case of the families and friends, as an amusement activity. There were three different representations of Saint Helen and the city of Skövde, each of them with its own environment and characteristics. The construction of the narrative in each media, i.e., the exhibition, the game, the school lesson, is based, in general, on the same information, but the plots and stories are different. The players constructed their own narrative version of the overall experience; their perspective of history and storytelling was influenced by the narrative versions the players had been exposed to. "She was young and she was chased just as she was chased in history - when she was chased by the relatives of the daughter's husband."

The same person Elin was represented using three different media. Players seemed to enjoy the fact that Elin was a living character that played with them; they did things "together", shared with the character, helped and were helped. It did not actually seem relevant to the players' experience that the Elin in the game was not real. While the content of the media used at the museum and the schools was perceived as factual, i.e., Elin was a historical character, Skövde is a city that was re-built and its industry developed, in the environment of the game, the players were part of the history of a place that was re-born from the ashes, taking part in the hero's effort to guard the city.

\section{CONCLUSION}

The Game, The Mystery of Elin (Elins Mysterium), awakens the fantasy and curiosity of children by challenging their general knowledge and skills. Without really noticing, players increase their knowledge of the heritage of an area, the central streets of Skövde that during the time they are playing becomes the game arena. Players use features of the platform application and features of the iPad, such as compass, GPS, camera and image recognition to resolve puzzles by searching for symbols, counting objects, and finding buildings, plazas and parks.

Children's interpretation of history through the game is rather unique to each player. The imagination of children with previous knowledge about the history of Skövde was slightly limited compared to the imagination of children who did not have much prior knowledge about the city, with regard to historical elements adapted and incorporated into the storytelling of the game. The main character of the game, a young Elin, serves as the connection between the factual and fictional worlds. She tells a story through a comic strip that captures the initial attention of the players with an imaginary narrative that encourages players to find five important sites in the center of the city as part of a puzzle. Players resolve the puzzles by learning more about the story that each piece represents. The story provides clues which give them the opportunity to reflect about each site. The sites, in the central city area, were selected by game writers from the relevant monuments and locations included in "The Cultural Environment Program for the Municipality of Skövde". The evaluation shows that children learned about Skövde's history when playing the game. Testimonies from the children pointed out that players selected elements of heritage and history with significance to them and merged these elements with previous experiences and knowledge of the subject.

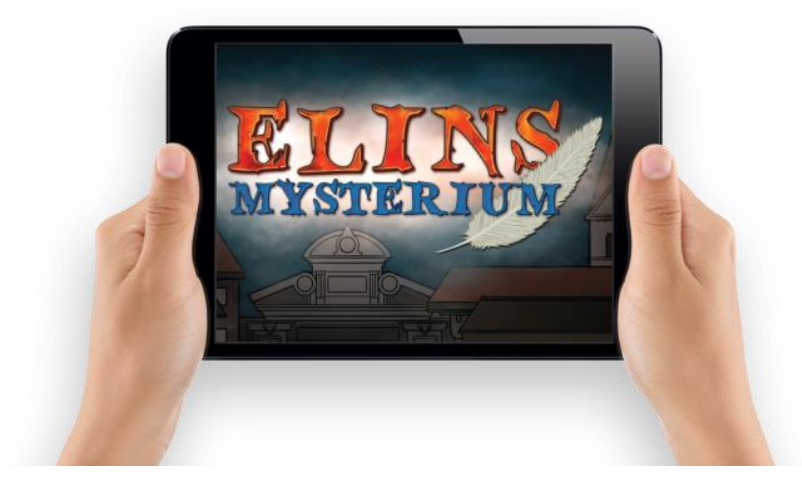

Figure 14. App available free of cost

The Mystery of Elin (Elin Mysterium) today provides an exciting experience that can be applicable in education as well as entertainment; it is an alternative activity used to guide tourists around the central area of the city of Skövde, as well as an introduction to its history.

The amusement aspect of this game resides in its continuous challenges. Tasks that are not hard to solve but require patience with regard to counting, observing, and walking around. Although players, after the start, might find the instructions of the game somewhat unclear or require help from an adult to interpret the roman numbers, the introductory comic strip and the voice of Elin indicate that an adventure has started, with suspense and curiosity along the way. 
This game can contribute to learning in the schools and has the potential to incorporate challenges from a variety of disciplines.

The evaluation shows that the game played outdoors and requiring motion in combination with mobile terminals has limitations, in terms of hearing sound and reading text from the terminal, especially with a story-driven game. Graphics can play a more important role as the interface between game worlds. The game's graphics can be made more noticeable for players in outdoor daylight conditions by applying colors and forms, while the players' distance to the screen also affects their ability to understand the story. Other limitations can occur over time, as the real environment changes or is restored.

The game is engaging at the beginning, but the instructions provided thereafter are rather unclear, which, coupled with the fact that the first challenge is more difficult than those following, may cause a sense of uncertainty in the player. In addition, the interaction design needs improvement, however, statistics on the clarity of the game show that it did not affect the overall experience.

The duration of the game, as well as the language used in the text to address the targeted players, seemed appropriate. Statistical information about the players at each of the sites shows that the first three places were remembered more than the last two. This could be attributed to the natural attention span of children. It could also be that the most exciting technology tools were used at the first three sites.

Playing the game in a group is a satisfactory experience, especially when the group's members are around the same age. The ideal number of players is two or three, but playing individually is fun as well.

A relevant consideration in the design of the game was the connection between the story and the tasks. This is where one of the major design challenges resided. Excited by the freedom of moving around in a space that was turned into a game environment, the children, motivated by the spirit of competition, tended to focus on moving forward with the quests and did not notice that they were actually learning something at the same time.

In regard to the design, it would be beneficial to alter the consecutive order of the sites, thus increasing the challenge and excitement of using the compass. This feature and sorting the quests and tasks at each site according to the age of the player would enhance the dynamics between the players and the game, as well as provide flexibility and ease. Altering the consecutive order would also allow the story to be structured in various ways.

Children learnt by playing the game. For instance, they learned about the location of five important sites in the central city area, thereby gaining a sense of security and control over their own place in it. Most players identified the moment in history of those places and its significance today; e.g., the fire that consumed the city and its consequent re-construction. They are probably more curious about and attentive to details on facades and signs, buildings and plazas, after playing the game. The evaluation helped to identify the potential advantages of a further enhanced version of the game.

Players were exposed to various forms of representation of Saint Helen and the history of Skövde, such as the introductory video of The Legend of Elin at the city's museum, the exhibition itself, and the material seen during lessons at school. Although the game was one of several forms the municipality used to promote the culture of Skövde, each participant nevertheless made his/her own interpretation of the person Elin and Skövde's history. Players built it from fragments of the story captured when playing the game, by connecting pieces of a puzzle to be assembled in a quest, using key words and images fed with historical significance and directly related to the story, e.g., fire (in the narration) - Fenix (five letters puzzle) and Egyptian symbols (images). After adaptation, writer students created a story that contained insertions of history and information. The story went along through various forms. Fragments of information were spread along the game, in the screen graphics, game elements of the real world and inserts in the characters' speech; each time the players succeeded in achieving the quests, they received new pieces of the story.

The transfer of a cultural content inspired in pervasive games as a medium resulted in rich experiences of imagination and fun. It is certain that expressions used to introduce Elin and Skövde in the children's mind were better assimilated by an adaptation process. When the game designers and game writers thought about creating the story and the gameplay, they initiated a process of adapting the fundamental meaning of the content to a new representation applicable in a mixed gaming environment, by providing that specific features take the form of a game. The mechanics motivated players to gain more pieces of the story because they were fun to resolve, which allowed them to perform a critical role in helping the main character solve the mystery and establishing a bond with the hero by sharing her features.

This study was an approach to combine several forms of media in order to create a historical adventure specific to a unique context; in that sense, this experience could probably be emulated or transferred to other sites or tourist destinations of historical interest.

\section{ACKNOWLEDGMENTS}

Our thanks to Rena Ahmad and Lidia Maldonado for conducting many of the interviews of school children and for actively participating during the evaluation sessions.

Our gratitude to the head teachers of the participant schools, Gunnar Lord and Göran Nilsson, for supporting the activity in the game evaluation.

\section{REFERENCES}

[1] Adams, E. \& Dormans, J., 2012. Game Mechanics: Advanced Game Design. Berkeley, CA: New Riders.

[2] Ardito, C. o.a., 2011. Designing Pervasive Games for Learning. i: A. M. (Ed.), red. Design, User Experience, and Usability. Berlin Heidelberg: Springer-Verlag, pp. 99-108.

[3] Bryman, A., 2002. Samhällsvetenskapliga metoder. översättade från Engelska first edition 2001 av Björn Nilsson red. Malmö: Liber AB;Oxford University Press.

[4] Holmström, C., 2014. Folkmängd efter region, ålder och år, Stockholm: ekonomifakta.se.

[5] Jegers, K., 2009. Pervasive Gameflow: Identifying and exploring the Mechanisms of Play Enjoyment in Pervasive Games, Umeå, Sweden: Umeå University, Inst för Informatik.

[6] Jenkins, H., 2004. Game Design as Narrative Arquitecture. i: N. Wardrip-Fruin \& P. Harrigan, red. First Person: New 
Media as Story, Performance and Game. Cambridge, MA: MIT Press., pp. 118-130.

[7] Ros, A., 2014. Elin the Legend: A saint as an animated nonverbal educational character, Skövde, Sweden: Högskolan i Skövde. School of Humanities and Informatics. http://urn.kb.se/resolve?urn=urn:nbn:se:his:diva-8964.

[8] Rouse III, R., 2005. Game Design: Theory \& Practice. Second Edition. red. USA: Worldware Publishing, Inc..
[9] Skövde Kommun, 2012. Kulturmiljöprogram för Skövde Kommun / Skövde Kommun/Kultur. [Online]

Available at:

http://www.skovde.se/upload/ByggaBo/BilderPBLK/Kultur miljo/Sk\%c3\%b6vde\%20KMP\%2020120216\%20Staden\%2 0Inledning $\% 20$ Historik $\% 20$ reviderad.pdf?epslanguage $=$ SV [Använd 10 Sep 2013]. 